\title{
ANTESEDEN INTENSI WIRAUSAHA BERDASARKAN SOCIAL COGNITIVE CAREER THEORY
}

\author{
Dede Kurnia* $^{*}$ \\ STKIP Majenang, Indonesia \\ Muhammad Ngasifudin \\ STKIP Majenang, Indonesia
}

\begin{abstract}
This study aims to determine and analyze the mediating effect of entrepreneurial outcome expectations and entrepreneurial attitude on the influence of entrepreneurial self-efficacy on entrepreneurial intention. This study uses a quantitative approach with explanatory survey methods. The data collection tool in this study uses a questionnaire. In contrast, in determining the number of samples, this study applied convenience sampling so as obtain 75 young people in district Sukaresik, Tasikmalaya. The analysis technique carried out in this study was regression-based Serial Multiple Mediators using Macro Process software developed by Andrew F. Hayes. The result showed that entrepreneurial self-efficacy to entrepreneurial intention has a direct influence. In addition, entrepreneurial outcome expectations and entrepreneurial attitudes also serially mediate the effect of entrepreneurial self-efficacy on entrepreneurial intentions. The originality of this research is the adaptation of Social Cognitive Career Theory into entrepreneurial intention research which is still relatively rare. This research has a theoretical contribution to research on entrepreneurial intentions, which is still dominated by the theory of planned behavior developed by Icek Ajzen.
\end{abstract}

JEL : M20, A22, I20.

Keywords : entrepreneurial outcome expectations, entrepreneurial attitude, entrepreneurial intention.

\begin{abstract}
ABSTRAK
Penelitian ini bertujuan untuk mengetahui serta menganalisis efek mediasi harapan hasil kewirausahaan dan sikap kewirausahaan pada pengaruh efikasi diri kewirausahaan terhadap intensi wirausaha. Penelitian ini menggunakan pendekatan kuantitatif dengan metode survei eksplanotori. Adapun alat pengumpulan data penelitian ini menggunakan kuesioner, sedangkan dalam proses penentuan sampel penelitian ini menerapkan teknik convenience sampling sehingga didapatkan 75 orang pemuda di Kecamatan Sukaresik Kabupaten Tasikmalaya. Teknik analisis data yang dilakukan pada penelitian ini Analisis Mediasi Serial Berbasis Pendekatan Regresi dengan menggunakan Software Macro PROCESS yang dikembangkan oleh Andrew F. Hayes. Hasil temuan ini menunjukkan bahwa efikasi diri kewirausahaan berpengaruh secara langsung terhadap intensi wirausaha, selain itu harapan hasil kewirausahaan dan sikap kewirausahaan juga secara serial memediasi pengaruh efikasi diri kewirausahaan terhadap intensi wirausaha. Orisinalitas dari penelitian ini adalah adaptasi Social Cognitive Career Theory ke dalam riset intensi wirausaha yang masih relatif jarang dilakukan. Penelitian ini memiliki kontribusi teoretis dalam riset-riset intensi kewirausahaan yang selama ini masih didominasi oleh theory planned behavior yang dikembangkan oleh Icek Ajzen.
\end{abstract}

Kata Kunci : harapan hasil kewirausahaan, sikap wirausaha, intensi wirausaha.

\section{PENDAHULUAN}

Wirausaha sebagai penggerak sektor produktif, inovasi dan usaha telah dianggap sebagai penentu pertumbuhan ekonomi dan kemakmuran bagi suatu negara (Bhuiyan \& Ivlevs, 2019; DíazGarcía \& Jiménez-Moreno, 2010; Doanh \& Bernat, 2019; Glaeser, Kerr \& Kerr, 2015; Kasabov, 2016). Banyaknya efek positif dari aktivitas wirausaha membuat banyak negara mempromosikan

\footnotetext{
*Email : dedekurnia50@gmail.com

Received: 10-06-2021, Accepted: 10-12-2021, Published : 28-12-2021

P-ISSN : 2087-9954, E-ISSN : 2550-0066. DOI : http://dx.doi.org/10.26418/jebik.v10i3.47150
} 
program-program kewirausahaan agar generasi muda tertarik untuk berwirausaha (Ataei, Karimi, Ghadermazi \& Norouzi, 2020). Di sisi lain, agar promosi program kewirausahaan dapat berhasil dan terlahir banyak generasi muda yang tertarik untuk berwirausaha, tentunya perlu juga diketahui faktor yang mempengaruhi individu agar memilih wirausaha sebagai pilihan karier di masa depan. Terkait dengan hal itu, beberapa riset menunjukkan bahwa intensi wirausaha merupakan anteseden dari sebuah perilaku wirausaha (Liñán \& Fayolle, 2015). Hal itu berarti bahwa intensi wirausaha yang dimiliki seseorang dapat menjadi indikasi bahwa pada waktu yang akan datang individu tersebut akan merealisasikan wirausaha sebagai pilihan karier (Santos \& Liguori, 2019). Penelitian mengenai intensi wirausaha menjadi tema yang selalu menarik dan penting untuk dilakukan sebab hal tersebut relevan dengan upaya memprediksi perilaku kewirausahaan itu sendiri. Terkait dengan hal tersebut, beberapa peneliti telah mengemukakan bahwa Teori Perilaku Terencana (Theory Planned Behavior) beserta tiga prediktor utamanya dapat memprediksi sebuah intensi wirausaha (Farani, Karimi \& Motaghed, 2017; Ferreira, Raposo, Rodrigues, Dinis \& Do Paco, 2012). Ketiga prediktor tersebut terdiri dari norma subjektif (subjective norm), sikap personal (attitude), dan persepsi kontrol perilaku (perceived behavioral control) (Fishbein \& Ajzen, 1975).

Teori Perilaku Terencana sebagai sebuah kerangka model yang cukup mapan dalam memprediksi intensi masih dianggap sebagai model yang kurang kompleks dan integratif, sehingga para pakar berpandangan bahwa masih diperlukan sebuah model alternatif yang lebih integratif dan kompleks dengan mempertimbangkan variabel-variabel lain baik dalam bentuk moderasi dan mediasi (Barnir, Watson \& Hutchins, 2011; Fitzsimmons \& Douglas, 2011; Pollack, Vanepps \& Hayes, 2012). Terkait dengan hal tersebut, diperlukan sebuah model konseptual yang dapat melengkapi kekurangan dalam model dasar dari Teori Perilaku Terencana agar prediksi terhadap intensi wirausaha bisa lebih komprehensif dan integratif.

Di dalam hal ini, Social Cognitive Career Theory (SCCT) merupakan model teori yang cukup kompleks dan integratif sehingga dapat diajukan sebagai model alternatif untuk menjelaskan intensi wirausaha dari perspektif teoretis yang berbeda. Secara konseptual SCCT menekankan pada kompleksitas, keragaman mekanisme dan kondisi yang penting untuk intensi wirausaha. Hal tersebut tentu berbeda dengan model Teori Perilaku Terencana (TPB) yang cenderung mengasumsikan bahwa kewirausahaan sebagai proses berurutan (Santos \& Liguori, 2019).

Kendati pun SCCT diyakini sebagai model baru yang cukup kompleks dan integratif dalam menjelaskan profesi yang akan dipilih di masa depan (Brown, Lent, Telander \& Tramayne, 2011), namun penggunaanya dalam penelitian dan pengujian SCCT secara empiris dalam konteks intensi wirausaha masih sangat jarang dilakukan (Brown \& Lent, 2019). Selain itu, riset empiris mengenai SCCT masih perlu dilakukan sebagaimana direkomendasikan oleh riset yang dilakukan untuk mengetahui anteseden intensi wirausaha dari perspektif SCCT itu sendiri (Liguori, Bendickson \& Mcdowell, 2017). Fakta tersebut menjadi sebuah research gap yang mendasari penelitian ini dilakukan.

Penelitian ini menjelaskan efek mediasi harapan hasil kewirausahaan dan sikap kewirausahaan baik secara parsial atau secara serial pada pengaruh efikasi kewirausahaan terhadap intensi wirausaha. Harapan hasil kewirausahaan ditempatkan sebagai variabel mediasi dengan pertimbangan bahwa tingginya efikasi diri akan berimplikasi pada tingginya harapan hasil seorang individu (Lent \& Brown, 2008). Adapun sikap kewirausahaan ditempatkan sebagai variabel mediasi dengan asumsi bahwa individu yang memiliki tingkat efikasi diri yang tinggi maka akan 
melahirkan sikap yang lebih positif dalam sebuah aktivitas (Devonish, Alleyne, Charles-Soverall, Marshall \& Pounder, 2010). Selanjutnya efek mediasi serial akan diuji untuk melihat bagaimana efek mediasi yang diberikan oleh harapan hasil kewirausahaan dan sikap kewirausahaan secara bersama-sama pada efikasi diri kewirausahaan terhadap intensi wirausaha.

Merujuk pada hasil penelitian empiris terdahulu diketahui bahwa masih didapatkan temuan yang inkonsisten terkait pengaruh aspek demografi seperti gender dan latar belakang keluarga terhadap kemunculan intensi wirausaha pada seorang individu. Beberapa diantaranya tampak dalam penelitian yang dilakukan oleh Chaudhary (2017), Smith \& Combs (2016) yang menunjukkan bahwa intensi wirausaha antara laki-laki dan perempuan tidak terdapat perbedaan. Temuan tersebut bertentangan dengan hasil penelitian Joensuu, Viljamaa, Varama \& Tornikoski (2013) dan juga temuan dari penelitian yang dilakukan lebih dari satu dekade sebelumnya yang menunjukkan bahwa individu yang memiliki gender perempuan cenderung memiliki intensi wirausaha lebih rendah daripada laki-laki. Inkonsistensi hasil temuan sebelumnya mengenai gender dan latar belakang keluarga dalam intensi wirausaha menjadi pertimbangan untuk memasukkan keduanya pada model konseptual penelitian (lihat Gambar 1) sebagai variabel kontrol dengan tujuan agar hasil penelitian bersifat lebih spesifik, tidak bias dan diperoleh simpulan yang utuh mengenai tingkat intensi wirausaha pada gender laki-laki dan perempuan.

Penelitian ini membahas beberapa pertanyaan penting: pertama, apakah efikasi diri kewirausahaan mempengaruhi intensi wirausaha secara langsung?. Kedua, apakah harapan hasil kewirausahaan dan sikap kewirausahaan memberikan efek mediasi secara parsial atau secara serial pada pengaruh efikasi diri kewirausahaan terhadap intensi wirausaha?. Secara konseptual tujuan yang ingin dicapai dalam penelitian ini adalah untuk mengembangkan pendekatan teoretikal baru untuk menjelaskan anteseden intensi wirausaha dari pendekatan Social Cognitive Career Theory (SCCT). Secara operasional penelitian ini bertujuan untuk mensintesis dan menguji secara empiris kedua pertanyaan penelitian yang telah diajukan.

\section{KAJIAN LITERATUR}

\subsection{Social Cognitive Career Theory}

Social Cognitive Career Theory (SCCT) merupakan sebuah teori yang dikembangkan oleh Robert W. Lent, Steven D. Brown, and Gail Hackett pada 1994 (Lent, Brown \& Hackett, 2002). Pada dasarnya dikembangkan dari teori sosial kognitif yang digagas oleh Bandura (Santos \& Liguori, 2019). SCCT berusaha menjelaskan tiga aspek yang saling terkait dari pengembangan karir: (1) bagaimana minat akademik dan karir dasar berkembang, (2) bagaimana pilihan pendidikan dan karir dibuat, dan (3) bagaimana kesuksesan akademik dan karir diperoleh. Secara konseptual, SCCT menekankan pada interaksi antara self-referent dengan proses sosial yang memandu perilaku seseorang. Di samping itu, pada beberapa literatur yang mendiskusikan karier seorang individu, SCCT merupakan sebuah teori mapan yang diterima banyak pihak dan terbukti sangat heuristik untuk memahami proses psikologis yang mendasari minat dan tujuan karier seseorang (Lent et al., 2002).

Model ini memuat tiga tujuan utama yaitu untuk tujuan pengembangan karier, minat akademis, pengambilan pilihan, serta kinerja (Brown \& Lent, 2019; Lent, Brown \& Hackett, 1994; Lent \& Brown, 2016; Robert \& Brown, 2013). Selain itu, Social Cognitive Career Theory tersusun dari tiga konstruk utama, yaitu keyakinan efikasi diri (self-efficacy beliefs), hasil yang diharapkan 
(outcome expectations), dan tujuan (goals) (Lent et al., 2002). Secara sederhana efikasi diri merujuk pada keyakinan seseorang dalam konteks kapasitas diri untuk melakukan sesuatu tindakan tertentu. Adapun harapan hasil merupakan konsekuensi yang hendak diinginkan dari sebuah tindakan yang dilakukan. Sementara itu, tujuan dapat didefinisikan sebagai tekad untuk terlibat dalam aktivitas tertentu (Lent et al., 2002).

Di sisi lain, penelitian ini melibatkan tiga prediktor yang digunakan untuk meneliti intensi wirausaha yakni efikasi diri kewirausahaan, harapan hasil kewirausahaan, dan sikap kewirausahaan. Ditambahkannya sikap kewirausahaan sebagai variabel yang akan diteliti mengacu pada temuan dalam riset-riset sebelumnya yang mengemukakan bahwa sikap kewirausahaan seseorang secara signifikan mempengaruhi intensi wirausaha seseorang (Devonish et al., 2010; Liguori, Winkler, Vanevenhoven, Winkel, James, 2019; Zhang, Wei, Sung \& Tung, 2019).

\subsection{Intensi Wirausaha}

Pada kajian psikologi sosial, intensi merupakan anteseden dari sebuah perilaku yang paling mendesak dan penting (Filho, Silva, Moraes, Fernandes, \& Morales, 2015), atau dapat juga didefinisikan sebagai orientasi mental seperti keinginan harapan untuk memilih profesi wirausaha di masa yang akan datang (Peng, Lu \& Kang, 2012). Tanpa sebuah niat maka tidak ada alasan untuk melakukan sebuah tindakan dengan tujuan tertentu, oleh sebab itu niat sangat penting untuk memahami sebuah perilaku (Lee \& Wong, 2004).

Kajian mengenai niat telah banyak melahirkan teori-teori yang cukup mapan seperti Theory of Entrepreneurial Event, Institutional Economic Theory, dan Theory of Planned Behavior sebagai teori yang paling banyak digunakan (Díaz-casero, Hernández-mogollon \& Roldán, 2014). Kendati demikian, penyelidikan mengenai niat kewirausahaan dalam penelitian ini tidak menggunakan salah satu dari ketiga teori yang ada, melainkan menggunakan SCCT sebagai model teorinya dengan asumsi bahwa harapan hasil kewirausahaan, efikasi diri kewirausahaan, dan sikap kewirausahaan saling terkait sehingga pada akhirnya mengarah pada pembentukan intensi wirausaha.

\subsection{Efikasi Diri Kewirausahaan}

Efikasi diri merupakan berasal dari teori belajar sosial Bandura (1977), dengan mengacu pada keyakinan seorang dalam kemampuannya untuk melakukan suatu tindakan (Bandura, 1997). Pada beberapa literatur ditemukan bahwa individu yang memiliki kepercayaan terhadap dirinya sendiri untuk melakukan suatu aktivitas, maka akan cenderung memiliki upaya, ketekunan, serta kinerja yang lebih baik (Liguori et al., 2017).

Pada konteks kewirausahaan, efikasi diri telah bertransformasi sebagai domain yang lebih spesifik dengan menjadi efikasi diri kewirausahaan yang merujuk pada keyakinan seseorang pada kemampuannya untuk berhasil melakukan berbagai peran dan aktivitas yang berkaitan dengan kewirausahaan (Cardon \& Kirk, 2015; Drnovšek, Wincent \& Cardon, 2010). Pengukuran efikasi diri kewirausahaan dalam penelitian ini mengadopsi skala ukur yang dikembangkan oleh Wang, Tseng \& Wang (2020).

Riset empiris yang dilakukan oleh Cheen, Greene \& Crick (1998), Santos \& Liguori (2019), Shi, Yao \& Wu (2019) menunjukkan bahwa efikasi diri kewirausahaan memberikan pengaruh positif terhadap intensi wirausaha. Selanjutnya riset yang dilakukan oleh Liguori et al. (2019) menunjukkan bahwa efikasi diri kewirausahaan juga memberikan pengaruh positif terhadap 
harapan hasil kewirausahaan, dengan asumsi bahwa individu yang memiliki efikasi diri kewirausahaan yang tinggi cenderung memiliki harapan hasil yang baik (Fouad \& Guillen, 2006). Di sisi lain, Devonish et al. (2010) mengemukakan bahwa sikap kewirausahaan seseorang juga dipengaruhi oleh efikasi diri kewirausahaan.

\subsection{Harapan Hasil Kewirausahaan}

Secara umum harapan hasil merupakan keyakinan seseorang mengenai konsekuensi positif atau negatif dari sebuah tindakan yang dilakukan. Adapun dalam konteks yang spesifik, harapan hasil kewirausahaan merujuk pada konsekuensi yang diharapkan seseorang atas rencana keterlibatannya dalam aktivitas kewirausahaan (Vanevenhoven \& Liguori, 2013). Harapan hasil kewirausahaan yang muncul dari seseorang bisa berbeda-beda tergantung pada respons positif atau negatif terhadap kewirausahaan dari seorang individu. Jika seseorang memiliki harapan hasil yang positif maka aktivitas kewirausahaan akan dianggap sebagai kegiatan yang menyenangkan dan bermanfaat, sebaliknya jika seseorang memiliki harapan hasil negatif maka aktivitas kewirausahaan akan dianggap sebagai aktivitas yang menjenuhkan, pemicu stres, dan tidak memberikan manfaat.

Pada beberapa pengujian empiris, diketahui bahwa harapan hasil kewirausahaan secara parsial ditentukan oleh efikasi diri kewirausahaan (Lent \& Brown, 2008), hal tersebut berarti bahwa seseorang yang memiliki efikasi kewirausahaan lebih baik, maka akan cenderung memiliki harapan hasil kewirausahaan yang lebih positif, begitu pun sebaliknya individu yang memiliki efikasi kewirausahaan rendah, maka akan cenderung memiliki harapan hasil kewirausahaan yang negatif. Riset yang dilakukan oleh Liguori et al. (2019) dan Schwarz, Wdowiak, Almer-Jarz \& Breitenecker (2009) menunjukkan bahwa harapan hasil kewirausahaan berpengaruh positif pada sikap kewirausahaan, sementara itu temuan dari penelitian yang dilakukan oleh Santos \& Liguori (2019) juga menunjukkan bahwa harapan hasil kewirausahaan memberikan pengaruh yang positif terhadap intensi wirausaha.

\subsection{Sikap Kewirausahaan}

Sikap kewirausahaan merujuk pada penilaian pribadi positif atau negatif mereka tentang menjadi seorang pengusaha, dan mencakup pertimbangan afektif dan evaluatif (Liguori et al., 2019). Di dalam beberapa penelitian ditemukan bahwa efikasi diri kewirausahaan berdampak pada munculnya sikap kewirausahaan, oleh sebab itu semakin tinggi efikasi diri kewirausahaan maka sikap kewirausahaannya akan cenderung lebih tinggi (Devonish et al., 2010).

Pada penelitian ini, sikap wirausaha ditempatkan sebagai variabel mediasi kedua yang memediasi pengaruh efikasi diri kewirausahaan dan harapan hasil kewirausahaan dengan pertimbangan bahwa sikap seseorang akan sangat dipengaruhi oleh persepsi orang tersebut mengenai kapasitas dirinya sendiri. Pada proses ini apabila seseorang memiliki keyakinan untuk berhasil dalam aktivitas wirausaha, maka hal tersebut akan berdampak pada harapan hasil kewirausahaan yang akan semakin positif sehingga berdampak pada terbentuknya sikap kewirausahaan seseorang (Liguori et al., 2019; Segal, Borgia \& Schoenfeld, 2002).

\subsection{Variabel Kontrol}

Penelitian dalam bidang intensi wirausaha dengan melibatkan variabel sosio-demografi menjadi hal yang menarik dan penting untuk dikaji, sebab beberapa riset sebelumnya telah menunjukkan bahwa faktor-faktor sosio-demografi seperti latar belakang keluarga dan gender 
mempengaruhi intensi wirausaha seseorang (Chaudhary, 2017; Kautonen, Luoto \& Tornikuski, 2010; Lee, Kam, Foo \& Leung, 2011; Nguyen, 2018; Solesvik, 2013; Zhang, Duysters \& Cloodt, 2013). Kendati demikian dalam konteks penelitian ini, faktor sosio-demografi diposisikan sebagai variabel kontrol agar pengaruh dari extraneous variable dapat diminimalkan atau bahkan dipurifikasi sehingga hasil analisis mampu menjelaskan fenomena dengan lebih optimal (Carlson $\& \mathrm{Wu}, 2012)$.

\subsection{Kerangka Penelitian}

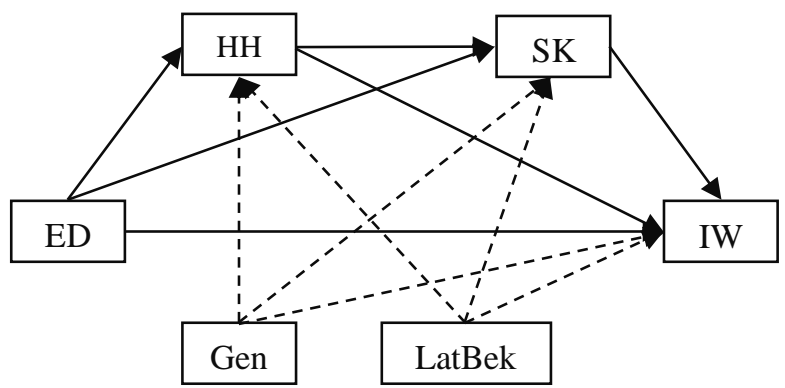

Gambar 1. Kerangka Penelitian

Berdasarkan kerangka penelitian yang disajikan dalam Gambar 1, maka dapat dirumuskan hipotesis sebagai berikut:

$\mathrm{H}_{1}$ : Efikasi diri kewirausahaan berpengaruh terhadap harapan hasil kewirausahaan.

$\mathrm{H}_{2}$ : Harapan hasil kewirausahaan memediasi pengaruh efikasi diri kewirausahaan terhadap intensi wirausaha.

$\mathrm{H}_{3}$ : Sikap kewirausahaan memediasi pengaruh efikasi diri kewirausahaan terhadap intensi wirausaha.

$\mathrm{H}_{4}$ : Sikap kewirausahaan dan harapan hasil kewirausahaan secara serial memediasi pengaruh efikasi diri kewirausahaan terhadap intensi wirausaha.

\section{METODE PENELITIAN}

Penelitian ini menggunakan pendekatan kuantitatif dengan metode survei eksplanatori, yaitu sebuah metode penelitian yang dilakukan untuk menjelaskan sebuah hubungan dua variabel atau lebih dengan pengambilan data dari suatu kelompok subjek tanpa dilakukan intervensi terlebih dahulu (Silalahi, 2010). Penelitian ini dilakukan di Kecamatan Sukaresik, Kabupaten Tasikmalaya dengan populasi seluruh pemuda dalam kategori milenial yang sedang dalam masa kuliah, adapun penarikan sampel didasarkan pada teknik convenience sampling sehingga didapatkan 75 responden. Mengacu pada rule of thumb dari Roscoe disebutkan bahwa ukuran sampel lebih dari 30 dan kurang dari 500 adalah tepat untuk kebanyakan penelitian dan Roscoe juga menyarankan agar dalam penelitian multivariat jumlah sampelnya minimal 10 kali lebih besar dari jumlah variabel yang ada (Sekaran \& Bougie, 2016). Jika demikian maka jumlah responden yang sebanyak 75 orang yang digunakan dalam penelitian ini telah memenuhi kecukupan. Pengumpulan data dilakukan dengan kuesioner yang akan disebar secara langsung. Adapun kuesioner mengenai efikasi diri kewirausahaan diukur dengan enam butir item dari kuesioner yang dikembangkan oleh Pihie \& Bagheri (2010), harapan hasil kewirausahaan diukur melalui empat item yang dikembangkan dari gagasan Kruger, Reilly \& Carsrud (2000), sikap kewirausahaan diukur melalui lima item dalam kuesioner yang dikembangkan oleh Solesvik (2013), serta intensi wirausaha dengan mengadaptasi tujuh item dalam kuesioner yang dikembangkan oleh Jena (2020). 
Penelitian ini melibatkan satu variabel independen yakni efikasi diri kewirausahaan, variabel dependen intensi wirausaha, serta dua variabel mediasi sikap kewirausahaan dan harapan hasil kewirausahaan sebagaimana direkomendasikan oleh Aguinis, Ramani \& Alabduljader (2018) dan Liguori et al. (2019). Di samping itu, penelitian juga melibatkan variabel kontrol nonperseptual berupa gender dan latar belakang keluarga yang mengendalikan variabel harapan hasil kewirausahaan, sikap wirausaha, dan intensi wirausaha. Di dalam hal ini penggunaan variabel kontrol bertujuan agar diketahuinya hubungan terkontrol antar variabel dan terukurnya kontribusi tambahan yang dibuat terhadap prediksi variabel dependen setelah pengaruh extraneous variable dari aspek sosio-demografi dikendalikan.

Analisis data dilakukan dengan berbasis pendekatan regresi dengan software Macro PROCESS versi 3.5 untuk SPSS sehingga dapat diketahui bagaimana pengaruh efikasi diri kewirausahaan terhadap intensi wirausaha secara langsung, dan mengetahui efek mediasi serial dari harapan hasil wirausaha serta sikap wirausaha dalam hubungan antara efikasi diri kewirausahaan terhadap intensi wirausaha. Pemilihan analisis mediasi serial dengan berbasis pendekatan regresi merujuk pada argumen Zhao, Lynch \& Chen (2010) yang menyebutkan bahwa Baron and Kenny's procedure untuk analisis mediasi memiliki beberapa kecacatan logika. Pada konteks itu, Zhao et al. (2010) memberikan rekomendasi satu tes bootstrap dari efek tidak langsung $\mathrm{a} \times \mathrm{b}$. Terkait dengan hal itu, analisis mediasi serial sebagaimana dikemukakan oleh Hayes (2018) telah memenuhi rekomendasi dan sekaligus melengkapi kekurangan dari Baron and Kenny's procedure sebagaimana telah disampaikan oleh Zhao et al. (2010).

\section{HASIL DAN PEMBAHASAN}

\subsection{Karakteristik Responden}

Responden dalam yang diambil dengan teknik convenience sampling terdiri dari total 75 orang yang terdiri dari latar belakang keluarga dan gender yang beragam. Secara rinci, proporsi responden penelitian berdasarkan perspektif gender meliputi $42 \%$ responden laki-laki dan 57\% responden perempuan. Di sisi lain, jika ditinjau berdasarkan perspektif latar belakang keluarga, diketahui bahwa $29 \%$ responden memiliki latar belakang keluarga wirausaha dan sisanya sebesar $67 \%$ responden berasal dari keluarga yang memiliki latar belakang non-wirausaha.

\subsection{Uji Hipotesis}

Sebelum uji hipotesis dengan Mediation Analysis dilaksanakan, terlebih dahulu dilakukan uji asumsi klasik untuk memastikan bahwa persamaan regresi yang nanti didapatkan memiliki ketepatan pada estimasi, tidak bias, serta konsisten. Hasil uji asumsi klasik disajikan pada Tabel 1.

Tabel 1. Uji Asumsi Klasik

\begin{tabular}{lcrrrrlrr}
\hline \multirow{2}{*}{ Variabel } & \multicolumn{2}{c}{ Multikolinieritas } & \multicolumn{2}{c}{ Heteroskedastis } & Normalitas & \multicolumn{2}{c}{ Linearitas } \\
\cline { 2 - 9 } & Tolereance & VIF & t & Sig. & Asymp. Sig. & F & Sig. \\
\hline EDK & 0,715 & 1,398 & 0,539 & 0,591 & & Linearity & 264,246 & 0,000 \\
HHK & 0,378 & 2,649 & $-0,775$ & 0,441 & 0,200 & DFL & 2,201 & 0,010 \\
SK & 0,344 & 2,908 & $-1,229$ & 0,223 & & & & \\
\hline
\end{tabular}

Merujuk pada hasil uji yang disajikan dalam Tabel 1 diketahui bahwa di dalam data yang akan diuji tidak terdapat gejala multikolinieritas, hal ini tampak dari nilai tolerance $>0,10$ dan nilai VIF $<10$. Pengujian asumsi heteroskedastis menggunakan Uji Park juga menunjukkan bahwa nilai sig $>0,05$ hal itu berarti bahwa dalam model regresi tidak terdapat gejala heteroskedastisitas. Adapun hasil uji normalitas dengan Kolmogorov-Smirnov memberikan hasil p (sig) $=0,200>$ 
0,005 yang bermakna bahwa residual berdistribusi normal. Pengujian linearitas juga menunjukkan hasil Sig = 0,000 (Sig. < 0,005) yang mengindikasikan bahwa hubungan variabel dapat dijelaskan dengan menggunakan model linier. Secara umum, hasil uji asumsi klasik sebagaimana tersaji dalam Tabel 1 menunjukkan bahwa data yang akan diuji dengan analisis regresi model Ordinary Least Square Analysis (OLS) telah memenuhi seluruh asumsi yang dipersyaratkan. Tahap selanjutnya dilakukan pengujian Mediation Analysis dengan pendekatan berbasis regresi OLS menggunakan Macro PROCESS sehingga didapatkan hasil pengujian sebagaimana disajikan dalam Tabel 2.

Tabel 2. Koefisien Analisis Model Mediasi dengan Kovariat

\begin{tabular}{|c|c|c|c|c|c|c|c|c|c|c|c|c|}
\hline & \multicolumn{4}{|c|}{ HHK (M } & \multicolumn{4}{|c|}{ SK $\left(M_{2}\right)$} & \multicolumn{4}{|c|}{ IW (Y) } \\
\hline & & Koef. & SE & p & & Koef. & SE & p & & Koef. & SE & p \\
\hline$\overline{\mathrm{EDK}}(\mathrm{X})$ & $a_{1}$ & 0,234 & 0,546 & 0,001 & $a_{2}$ & 0,117 & 0,044 & 0,011 & $c^{\prime}$ & 0,100 & 0,041 & 0,017 \\
\hline $\operatorname{HHK}\left(\mathrm{M}_{1}\right)$ & & - & - & - & $b_{1}$ & 0,761 & 0,086 & 0,000 & $b_{2}$ & 0,120 & 0,109 & 0,276 \\
\hline $\mathrm{SK}\left(\mathrm{M}_{2}\right)$ & & - & - & - & & - & - & - & $b_{3}$ & 0,706 & 0,104 & 0,000 \\
\hline $\operatorname{Gen}\left(\mathrm{C}_{1}\right)$ & $f_{1}$ & $-0,407$ & 1,376 & 0,767 & $g_{1}$ & $-1,177$ & 1,007 & 0,246 & $h_{1}$ & $-2,719$ & 0,888 & 0,003 \\
\hline Latbek $\left(\mathrm{C}_{2}\right)$ & $f_{2}$ & 0,592 & 1,870 & 0,691 & $g_{2}$ & 0,314 & 1,089 & 0,773 & $h_{2}$ & 0,207 & 0,952 & 0,828 \\
\hline Konstanta & $i M_{1}$ & 28,238 & 4,972 & 0,000 & $i M_{1}$ & 4,888 & 4,387 & 2,690 & $i M_{1}$ & 4,387 & 3,864 & 2,601 \\
\hline & & $=0,21$ & & & & $2=0,6$ & & & & $=0,7$ & & \\
\hline
\end{tabular}

Hasil analisis sebagaimana disajikan dalam Tabel 2 merupakan koefisien dari setiap jalur regresi dalam Gambar 2 berikut.

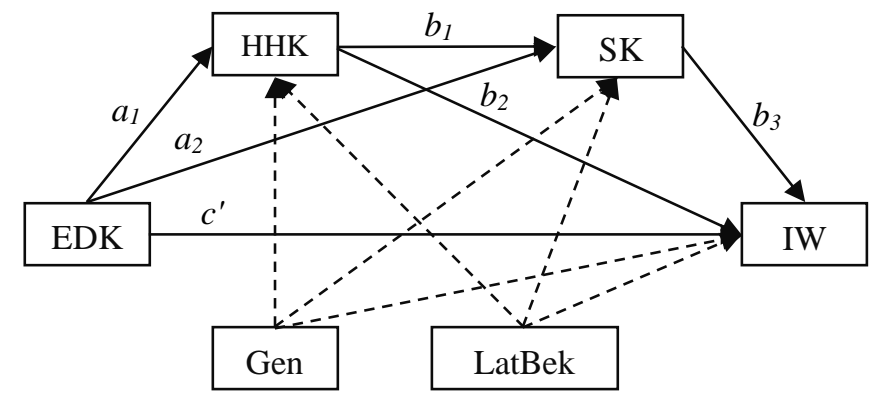

Gambar 2. Model Mediasi dengan Kovariat

Berdasarkan Tabel 2 dan Gambar 2 dapat diketahui efek mediasi langsung X terhadap Y (c'), efek mediasi tidak langsung $X$ terhadap $Y$ via $M_{1}\left(M_{1}=a_{1} b_{2}\right)$, efek mediasi tidak langsung $X$ terhadap $Y$ via $M_{2}\left(M_{2}=a_{2} b_{3}\right)$, efek mediasi tidak langsung $X$ terhadap $Y$ via $M_{1}$ dan $M_{2}\left(M_{1} M_{2}=\right.$ $\left.a_{1} b_{1} b_{3}\right)$, dan total efek mediasi tidak langsung X terhadap $Y\left(a_{1} b_{2}+a_{2} b_{3}+a_{1} b_{2} b_{3}\right)$. Di sisi lain, perlu juga diperhatikan bahwa analisis dengan menggunakan banyak kovariat pada variabel $\mathrm{Y}$ dan $\mathrm{M}$ maka prinsip $c=c^{\prime}+a_{1} b_{2}+a_{2} b_{3}+a_{1} b_{2} b_{3}$ menjadi tidak berlaku sehingga total efek langsung menjadi sulit diestimasi (Hayes, 2018). Selengkapnya disajikan dalam Tabel 3.

Tabel 3. Efek Mediasi

\begin{tabular}{|c|c|c|c|c|c|c|c|}
\hline & Efek & SE & $\mathbf{t}$ & $\mathbf{p}$ & LLCI & ULCI & Keterangan \\
\hline Efek Langsung & 0,100 & 0,041 & 2,443 & 0,017 & 0,018 & 0,181 & $\mathrm{H}_{0}$ ditolak \\
\hline Total Efek Tidak Langsung & 0,236 & 0,066 & & & 0,117 & 0,374 & $\mathrm{H}_{0}$ ditolak \\
\hline $\mathrm{EDK} \rightarrow \mathrm{HHK} \rightarrow \mathrm{IW}$ & 0,028 & 0,030 & & & $-0,028$ & 0,092 & $\mathrm{H}_{0}$ diterima \\
\hline $\mathrm{EDK} \rightarrow \mathrm{SK} \rightarrow \mathrm{IW}$ & 0,082 & 0,038 & & & 0,018 & 0,171 & $\mathrm{H}_{0}$ ditolak \\
\hline $\mathrm{EDK} \rightarrow \mathrm{HHK} \rightarrow \mathrm{SK} \rightarrow \mathrm{IW}$ & 0,125 & 0,044 & & & 0,050 & 0,223 & $\mathrm{H}_{0}$ ditolak \\
\hline
\end{tabular}

Hasil analisis dalam Tabel 3 menunjukkan bahwa efek langsung efikasi diri kewirausahaan (X) berpengaruh terhadap intensi wirausaha (Y) dengan koefisien efek sebesar 0,100, hal ini dapat 
dilihat dari bootstrap confidence interval berada di atas angka 0 dengan Lower-Level Confidence Interval (LLCI) 0,018 dan Upper-Level Confidence Interval (ULCI) sebesar 0,181. Hasil tersebut sekaligus membuktikan hipotesis satu $\left(\mathrm{H}_{1}\right)$ yang diajukan dalam penelitian. Temuan ini mengonfirmasi penelitian sebelumnya yang menunjukkan bahwa individu dengan efikasi diri kewirausahaan yang lebih tinggi cenderung memiliki niat kewirausahaan yang lebih tinggi karena individu tersebut lebih mungkin untuk percaya bahwa mereka juga memiliki ide yang dapat ditindaklanjuti (Drnovšek et al., 2010; Kickul, Marlino, Wilson \& Barbosa, 2008; Santi, Hamzah \& Rahmawati, 2017)

Temuan ini konsisten dengan Social Cognitive Carrier Theory (SCCT) yang menyebutkan bahwa level efikasi diri pada seorang individu akan menentukan ketekunan dan ketahanan dalam proses mencapai tujuan tertentu (Şahin, Karadağ \& Tuncer, 2019). Di sisi lain, beberapa ahli menyebutkan bahwa masuk ke dalam dunia wirausaha diyakini sebagai tindakan yang disengaja dengan melibatkan upaya berulang untuk mengontrol tindakan agar dapat mencapai hasil yang diinginkan. Pentingnya posisi efikasi diri kewirausahaan dalam proses pembentukan intensi wirausaha telah mendorong para ahli untuk secara teoretis mengusulkan efikasi diri kewirausahaan sebagai anteseden utama dari intensi wirausaha (Crespo, Belchior \& Costa, 2018; Laviolette, Lefebvre \& Brunel, 2012; Newman, Obschonka, Schwarz, Cohen \& Nielsen, 2019).

Pengujian terhadap hipotesis kedua $\left(\mathrm{H}_{2}\right)$ dengan Macro PROCESS menunjukkan koefisien efek mediasi sebesar 0,24 namun tidak signifikan secara statistik (-0,028-0,092). Hasil uji tersebut menjadi indikasi bahwa $\mathrm{H}_{0}$ diterima, sehingga dapat disimpulkan harapan hasil kewirausahaan tidak memediasi pengaruh efikasi diri kewirausahaan terhadap intensi wirausaha. Di sisi lain, meskipun hasil pengujian menunjukkan pengaruh yang positif, namun keputusan tersebut tidak dapat dijadikan acuan sebab tidak signifikan pada taraf 5\% atau bootstrap confidence interval berada di bawah angka nol yang berimplikasi pada diterimanya $\mathrm{H}_{0}$.

Berdasarkan hasil pengujian yang disajikan dalam Tabel 3, diketahui bahwa sikap kewirausahaan memediasi pengaruh efikasi diri kewirausahaan terhadap intensi wirausaha dengan koefisien efek sebesar 0,082 $(0,018-0,171)$. Hasil tersebut mengindikasikan bahwa $\mathrm{H}_{0}$ pada hipotesis ketiga ditolak dan hipotesis alternatif yang diajukan diterima, sehingga dapat disimpulkan jika sikap kewirausahaan memediasi pengaruh efikasi diri kewirausahaan terhadap intensi wirausaha. Temuan ini mengonfirmasi dan sekaligus konsisten dengan penelitian sebelumnya.

Sikap kewirausahaan yang memberikan efek mediasi pada efikasi diri kewirausahaan terhadap intensi wirausaha, dapat dimaknai bahwa semakin tinggi seorang individu memiliki penilaian yang positif terhadap kemampuan yang dimilikinya dalam konteks wirausaha, maka hal tersebut dapat melahirkan anggapan bahwa wirausaha sebagai bagian dari aktivitas yang akan memberikan keuntungan apabila dilaksanakan. Kendati demikian, efek mediasi yang diberikan oleh sikap kewirausahaan relatif lebih kecil jika dibandingkan dengan efek langsung dari efikasi diri kewirausahaan terhadap intensi wirausaha $(0,100>0,082)$.

Temuan terakhir di dalam penelitian ini menunjukkan bahwa secara serial harapan hasil kewirausahaan dan sikap wirausaha memberikan efek mediasi pada efikasi diri kewirausahaan terhadap intensi wirausaha dengan efek mediasi sebesar $0,125(0,050-0,223)$. Hal ini berarti bahwa $\mathrm{H}_{0}$ dalam hipotesis keempat ditolak. Apabila diamati secara saksama, efek mediasi yang diberikan oleh harapan hasil dan sikap kewirausahaan merupakan efek paling tinggi dibandingkan 
efek yang lain, ini menjadi indikasi bahwa temuan pada hipotesis terakhir ini sejalan dengan asumsi dasar dalam Social Cognitive Carrier Theory (SCCT).

Di dalam Social Cognitive Carrier Theory (SCCT) disebutkan bahwa penilaian individu mengenai kemampuannya sendiri untuk mengatur dan melaksanakan tindakan yang diperlukan untuk mencapai jenis kinerja yang ditentukan, akan berimplikasi pada keyakinan seseorang tentang konsekuensi atau efek dari melakukan perilaku tertentu (Tran \& Korflesch, 2016). Pada proses selanjutnya, semakin tinggi keyakinan individu untuk dapat melakukan sebuah aktivitas, maka hal tersebut akan berimplikasi pula pada tingkat keyakinan yang mempercayai bahwa aktivitas yang akan dilakukannya merupakan sebuah tindakan yang menguntungkan (Kusmintarti, Riwajanti \& Asdani, 2017).

Berdasarkan hasil pengujian sebagaimana disajikan dalam Tabel 3, dapat dipahami bahwa dalam konteks penelitian ini tidak terjadi efek mediasi penuh (perfect mediation), namun hanya terjadi efek mediasi parsial di mana hubungan antarvariabel tidak hanya melahirkan hubungan yang signifikan antara variabel mediator dan variabel dependennya, tetapi juga menunjukkan hubungan langsung yang signifikan antara variabel independen terhadap variabel dependen yang diajukan.

\subsection{Sensitivitas Terhadap Kovariat}

Hasil analisis yang disajikan dalam Tabel 2, pada dasarnya merupakan hasil analisis dengan melibatkan gender dan latar belakang keluarga sebagai kovariat, oleh sebab itu agar hasil penelitian lebih komperehensif untuk mengetahui bagaimana efek langsung X terhadap Y dan efek mediasi $\mathrm{M}_{1}$ serta $\mathrm{M}_{2}$, maka perlu dilakukan analisis ulang dengan tidak melibatkan variabel gender dan latar belakang keluarga sebagai kovariat. Analisis semacam itu perlu dilakukan untuk melihat seberapa sensitif atau peka hasil dari analisis pembanding tanpa kontrol terhadap penjelasan alternatif yang melibatkan variabel-variabel yang dikontrol (Hayes, 2018).

Analisis sensitivitas untuk mengetahui pengaruh variabel dependen dan mediasi tanpa melibatkan variabel kontrol gender dan latar belakang keluarga dilakukan dengan data, cara, serta software yang sama dengan analisis data sebelumnya. Adapun hasil analisis tanpa melibatkan variabel kontrol disajikan dalam Tabel 4 dan Tabel 5 berikut.

Tabel 4. Koefisien Analisis Model Mediasi Tanpa Kovariat

\begin{tabular}{|c|c|c|c|c|c|c|c|c|c|c|c|c|}
\hline & \multicolumn{4}{|c|}{ HHK (M) } & \multicolumn{4}{|c|}{ SK $\left(M_{2}\right)$} & \multicolumn{4}{|c|}{ IW (Y) } \\
\hline & & Koef. & SE & p & & Koef. & SE & p & & Koef. & SE & p \\
\hline$\overline{\mathrm{EDK}}(\mathrm{X})$ & $a_{1}$ & 0,234 & 0,531 & 0,000 & $a_{2}$ & 0,121 & 0,044 & 0,007 & $c^{\prime}$ & 0,106 & 0,043 & 0,014 \\
\hline $\operatorname{HHK}\left(\mathrm{M}_{1}\right)$ & & - & - & - & $b_{1}$ & 0,766 & 0,086 & 0,000 & $b_{2}$ & 0,095 & 0,115 & 0,411 \\
\hline $\operatorname{SK}\left(\mathrm{M}_{2}\right)$ & & - & - & - & & - & - & - & $b_{3}$ & 0,751 & 0,108 & 0,000 \\
\hline Konstanta & $i M_{1}$ & 28,602 & 3,155 & 0,000 & $i M_{1}$ & 3,135 & 3,384 & 0,358 & $i M_{1}$ & $-0,739$ & 3,144 & 0,814 \\
\hline & & $\begin{array}{l}\mathrm{R}_{2}=0,20 \\
\mathrm{~F}()=19,\end{array}$ & $\mathrm{p}=0$ & & & $\begin{array}{l}\mathrm{R}_{2}=0,6 \\
\mathrm{~F}()=68\end{array}$ & $63, p=$ &, 000 & & $\begin{array}{l}R_{2}=0,75 \\
()=71,7\end{array}$ & $4, p=$ & 000 \\
\hline
\end{tabular}

Tabel 5. Efek Mediasi Tanpa Kovariat

\begin{tabular}{|c|c|c|c|c|c|c|c|}
\hline & Efek & SE & $\mathbf{t}$ & $\mathbf{p}$ & LLCI & ULCI & Keterangan \\
\hline Efek Langsung & 0,106 & 0,042 & 2,497 & 0,014 & 0,021 & 0,191 & $\mathrm{H}_{0}$ ditolak \\
\hline Total Efek Tidak Langsung & 0,247 & 0,069 & & & 0,122 & 0,392 & $\mathrm{H}_{0}$ ditolak \\
\hline $\mathrm{EDK} \rightarrow \mathrm{HHK} \rightarrow \mathrm{IW}$ & 0,022 & 0,031 & & & $-0,039$ & 0,087 & $\mathrm{H}_{0}$ diterima \\
\hline $\mathrm{EDK} \rightarrow \mathrm{SK} \rightarrow \mathrm{IW}$ & 0,091 & 0,042 & & & 0,022 & 0,186 & $\mathrm{H}_{0}$ ditolak \\
\hline $\mathrm{EDK} \rightarrow \mathrm{HHK} \rightarrow \mathrm{SK} \rightarrow \mathrm{IW}$ & 0,134 & 0,045 & & & 0,056 & 0,234 & $\mathrm{H}_{0}$ ditolak \\
\hline
\end{tabular}


Berdasarkan hasil analisis sebagaimana tersaji dalam Tabel 4 dan Tabel 5 mengenai efek mediasi tanpa kovariat diketahui bahwa secara substansial dan secara statistik tidak ada yang benar-benar berubah, artinya hasil analisis data tanpa melibatkan gender dan latar belakang keluarga pun menunjukkan hasil yang cenderung sama dengan hasil analisis data dengan melibatkan variabel kontrol. Hasil analisis sensitivitas tersebut memberikan makna bahwa di dalam konteks penelitian ini, gender dan latar belakang keluarga bukan variabel perancu yang memberikan pengaruh cukup besar pada hubungan $\mathrm{X}$ ke $\mathrm{Y}$ atau $\mathrm{X}$ ke $\mathrm{Y}$ melalui $\mathrm{M}_{1} \mathrm{M}_{2}$. Kendati demikian, dapat dilihat bahwa koefisien $\mathrm{R}$-squared $\left(\mathrm{R}_{2}\right)$ menjadi lebih rendah ketika gender dan latar belakang keluarga tidak dilibatkan sebagai kovariat, artinya dapat dipahami bahwa secara statistik penambahan gender dan latar belakang keluarga sebagai kovariat menjadikan model konseptual lebih baik.

\section{SIMPULAN DAN REKOMENDASI}

Berdasarkan hasil penelitian yang dilakukan dapat disimpulkan bahwa efikasi diri kewirausahaan memberikan pengaruh langsung pada terbentuknya intensi wirausaha. Temuan itu menjawab pertanyaan penelitian yang pertama. Selanjutnya, harapan hasil kewirausahaan dan sikap wirausaha memberikan efek mediasi secara serial pada efikasi diri kewirausahaan terhadap intensi wirausaha, hal ini sekaligus menjawab pertanyaan kedua.

Di sisi lain, secara parsial hanya harapan hasil kewirausahaan saja yang secara statistik tidak memberikan efek mediasi pada efikasi diri kewirausahaan terhadap intensi wirausaha. Sementara itu, efek mediasi paling kuat diberikan oleh efek secara serial dari harapan hasil kewirausahaan dan sikap kewirausahaan, hal ini berarti bahwa peningkatan efikasi diri kewirausahaan akan menyebabkan peningkatan harapan hasil dan sikap kewirausahaan yang mengarah pada peningkatan intensi wirausaha.

Terkait dengan hasil riset tersebut, penelitian ini memberikan theoretical contribution dalam riset kewirausahaan. Melalui riset intensi kewirausahaan dengan model SCCT, maka riset fokus pada interaksi di antara variabel kognitif sosial pusat dalam membimbing pengembangan karir wirausaha. Rekomendasi yang dapat diberikan kepada keluarga dan lembaga pendidikan baik formal maupun non-formal berdasarkan penelitian ini adalah diperlukan kontribusi dari lembagalembaga relevan untuk bekerjasama meningkatkan kemampuan dasar pemuda dalam berwirausaha. Peningkatan kemampuan dasar tersebut diharapkan dapat meningkatkan keterampilan mereka dalam berwirausaha sehingga efikasi diri dalam konteks wirausaha dapat meningkat. Pada tahap selanjutnya, lembaga-lembaga pendidikan baik formal atau non-formal juga diharapkan lebih banyak melaksanakan kegiatan yang dapat meningkatkan keyakinan seseorang mengenai konsekuensi positif dari aktivitas wirausaha agar sikap wirausaha semakin terpupuk dengan baik sehingga dapat berimplikasi pada munculnya intensi wirausaha.

Salah satu keterbatasan dari riset ini adalah terlalu sedikit penggunaan variabel kontrol dari aspek sosio-demografi sehingga analisis sensitivitas terhadap kovariat menjadi kurang spesifik. Oleh sebab itu diharapkan penelitian di masa mendatang lebih banyak menggunakan variabel kontrol dari aspek sosio-demografi seperti usia dan latar belakang pendidikan agar analisis sensitivitas kovariat menunjukkan hasil yang lebih komprehensif dan spurious relationship dapat diantisipasi. Selain itu, keterbatasan kedua dari penelitian ini adalah jumlah sampel yang hanya berjumlah 75 responden di Kecamatan Sukaresik Kabupaten Tasikmalaya. 


\section{DAFTAR PUSTAKA}

Aguinis, H., Ramani, R. S., \& Alabduljader, N. (2018). What you see is what you get? Enhancing methodological transparency in management research. Academy of Management Annals, 12(1), 83-110.

Ataei, P., Karimi, H., Ghadermarzi, H., \& Norouzi, A. (2020). A conceptual model of entrepreneurial competencies and their impacts on rural youth's intention to launch SMEs. Journal of Rural Studies, 75(April 2019), 185-195.

Bandura, A. (1977). Social Learning Theory (A. Bandura (ed.)). Prentice Hall.

Bandura, A. (1997). Self-efficacy: The exercise of control. Freeman \& Company.

Barnir, A., Watson, E. W., \& Hutchins, M. H. (2011). Mediation and Moderated Mediation in the Relationship Among Role Models, Self-Efficacy, Entrepreneurial Career Intention, and Gender. Journal of Applied Social Ps, 41(2), 270-297.

Bhuiyan, M. F., \& Ivlevs, A. (2019). Micro-entrepreneurship and subjective well-being: Evidence from rural Bangladesh. Journal of Business Venturing, 34(4), 625-645.

Brown, S. D., \& Lent, R. W. (2019). Social Cognitive Career Theory at 25 : Progress in Studying the Domain Satisfaction and Career Self-Management Models. Journal of Career Assessment, 1-16.

Brown, S. D., Lent, R. W., Telander, K., \& Tramayne, S. (2011). Social cognitive career theory, conscientiousness, and work performance: A meta-analytic path analysis. Journal of Vocational Behavior, 79(1), 81-90.

Cardon, M. S., \& Kirk, C. P. (2015). Entrepreneurial Passion as Mediator of the Self-Efficacy to Persistence Relationship. Entrepreneurship Theory and Practice, 39(5), 1-24.

Carlson, K. D., \& Wu, J. (2012). The Illusion of Statistical Control: Control Variable Practice in Management Research. Organizational Research Methods, 15(3), 413-435.

Chaudhary, R. (2017). Demographic factors, personality and entrepreneurial inclination A study among Indian university students. Education + Training, 59(2), 171-187.

Cheen, C. C., Greene, P. G., \& Crick, A. (1998). Does Entrepreneurial Self-Efficacy Distinguish Entrepreneur From Managers? Journal of Business Venturing, 295-316.

Crespo, N. F., Belchior, R., \& Costa, E. B. (2018). Exploring individual differences in the relationship between entrepreneurial self-efficacy and intentions Evidence from Angola. Journal of Small Business and Enterprise Development, 27(1).

Devonish, D., Alleyne, P., Charles-Soverall, W., Marshall, A.Y \& Pounder, P. (2010). Explaining entrepreneurial intentions in the Caribbean. International Journal of Entrepreneurial Behavior \& Research, 16(2), 149-171.

Díaz-casero, J. C., Hernández-mogollon, R., \& Roldán, J. L. (2014). A structural model of the antecedents to entrepreneurial capacity. International Small Business Journal, 20(10), 123.

Díaz-García, M. C., \& Jiménez-Moreno, J. (2010). Entrepreneurial intention: The role of gender. International Entrepreneurship and Management Journal, 6(3), 261-283.

Doanh, D. C., \& Bernat, T. (2019). Entrepreneurial self-efficacy and intention among Vietnamese students: A meta-analytic path analysis based on the theory of planned behavior. 23rd International Conference on Knowledge-Based and Intelligent Information \& Engineering Systems, 159, 2447-2460. 
Drnovšek, M., Wincent, J., \& Cardon, M. S. (2010). Entrepreneurial self-efficacy and business start-up: developing a multi-dimensional definition. International Journal of Entrepreneurial Behaviour \& Research, 16(4), 329-348.

Farani, Y. A., Karimi, S., \& Motaghed, M. (2017). The role of entrepreneurial knowledge as a competence in shaping Iranian students' career intentions to start a new digital business. European Journal of Training and Development, 41(1), 83-100.

Ferreira, J. F., Raposo, M. L., Rodrigues, R. G., Dinis, A., \& Do Paco, A. (2012). A model of entrepreneurial intention: An application of the psychological and behavioral approaches. Journal of Small Business and Enterprise Development Vol., 10(3), 424-440.

Filho, L. S., Silva, V. M. S. da, Moraes, C. B. de, Fernandes, F. K., \& Morales, J. L. C. (2015). The Influence of Teachers With Non-Academic Experience on Entrepreneurial Intent Student Administration. Business and Management Review, 4(5), 751-760.

Fishbein, M., \& Ajzen, I. (1975). Belief, Attitude, Intention and Behaviour: An Introduction to Theory and Research. Addison-Wesley Publishing.

Fitzsimmons, J. R., \& Douglas, E. J. (2011). Interaction between feasibility and desirability in the formation of entrepreneurial intentions. Journal of Business Venturing, 26(4), 431-440.

Fouad, N. A., \& Guillen, A. (2006). Outcome expectations: Looking to the past and potential future. Journal of Career Assessment, 14(1), 130-142.

Glaeser, E. L., Kerr, S. P., \& Kerr, W. R. (2015). Entrepreneurship and Urban Growth: An Empirical Assessment with Historical Mines. Review of Economics and Statistics, 97(2), 498-520.

Hayes, A. F. (2018). Introduction to Mediation, Moderation, and Conditional Process Analysis: A regression-Based Approach (T. D. Little (ed.); 2nd ed.). The Guilford Press.

Jena, R. K. (2020). Measuring the impact of business management Student 's attitude towards entrepreneurship education on entrepreneurial intention: A case study. Computers in Human Behavior, 107(December 2018).

Joensuu, S., Viljamaa, A., Varama, E., \& Tornikoski, E. (2013). Development of entrepreneurial intention in higher education and the effect of gender - a latent growth curve analysis. Education + Training, 55(8), 781-803.

Kasabov, E. (2016). When an initiative promises more than it delivers: a multi-actor perspective of rural entrepreneurship difficulties and failure in Thailand. Entrepreneurship and Regional Development, 28(9-10), 681-703.

Kautonen, T., Luoto, S., \& Tornikoski, E. T. (2010). Influence of work history on entrepreneurial intentions in "prime age" and "third age": A preliminary study. International Small Business Journal, 28(6), 583-601.

Kickul, J., Marlino, D., Wilson, F., \& Barbosa, S. D. (2008). Are misalignments of perceptions and self-efficacy causing gender gaps in entrepreneurial intentions among our nation's teens? Journal of Small Business and Enterprise Development, 15(2), 321-335.

Kruger, N. F., Reilly, M. D., \& Carsrud, A. L. (2000). Competing models of entrepreneurial intentions. Journal of Business Venturing, 15(98), 411-432.

Kusmintarti, A., Riwajanti, N. I., \& Asdani, A. (2017). Pendidikan Kewirausahaan dan Intensi Kewirausahaan dengan Sikap Kewirausahaan sebagai Mediasi. Journal of Research and Applications: Accounting and Management, 2(2), 119. 
Laviolette, E. M., Lefebvre, M. R., \& Brunel, O. (2012). The impact of story bound entrepreneurial role models on self-efficacy and entrepreneurial intention. International Journal of Entrepreneurial Behaviour \& Research, 18(6), 720-742.

Lee, L., Kam, P., Foo, M. Der, \& Leung, A. (2011). Journal of Business Venturing Entrepreneurial intentions: The in $\mathrm{fl}$ uence of organizational and individual factors. Journal of Business Venturing, 26(1), 124-136.

Lee, S. H., \& Wong, P. K. (2004). An exploratory study of technopreneurial intentions: A career anchor perspective. Journal of Business Venturing, 19(1), 7-28.

Lent, R. W., \& Brown, S. D. (2008). Social Cognitive Career Theory and Subjective Well-Baing in the Context of Work. Journal of Career Assessment.

Lent, R. W., \& Brown, S. D. (2016). Social Cognitive Career Theory in a Diverse World: Guest Editors ' Introduction. Journal of Career Assessment, 1-3.

Lent, R. W., Brown, S. D., \& Hackett, G. (1994). Toward a Unifying Social Cognitive Theory of Career and Academic Interest, Choice, dan Performance. Journal of Vocational Behavior, 45 .

Lent, R. W., Brown, S. D., \& Hackett, G. (2002). Social Cognitive Career Theory. In Career Choice and Development (4th ed., p. 255). Jossey-Bass.

Liguori, E. W., Bendickson, J. S., \& Mcdowell, W. C. (2017). Revisiting entrepreneurial intentions: a social cognitive career theory approach. International Entrepreneurship and Management Journal, 14, 67-78.

Liguori, E., Winkler, C., Vanevenhoven, J., Winkel, D., James, M. (2019). Entrepreneurship as a career choice: intentions, attitudes, and outcome expectations. Journal of Small Business \& Entrepreneurship, $0(0), 1-21$.

Liñán, F., \& Fayolle, A. (2015). A systematic literature review on entrepreneurial intentions: citation, thematic analyses, and research agenda. International Entrepreneurship and Management Journal, 11, 907-933.

Newman, A., Obschonka, M., Schwarz, S., Cohen, M., \& Nielsen, I. (2019). Entrepreneurial selfefficacy: A systematic review ofthe literature on its theoretical foundations, measurement, antecedents and outcomes, and an agenda for future research. Journal of Vocational Behavior, 110, 403-419.

Nguyen, C. (2018). Demographic factors, family background and prior self-employment on entrepreneurial intention - Vietnamese business students are different: why? Journal of Global Entrepreneurship Research, 8(10), 2-17.

Peng, Z., Lu, G., \& Kang, H. (2012). Entrepreneurial Intentions and Its Influencing Factors: A Survey of the University Students in Xi' an China. Creative Education, 03(08), 95-100.

Pihie, L. Z. A., \& Bagheri, A. (2010). Entrepreneurial attitude and entrepreneurial efficacy of technical secondary school students. Journal of Vocational Education \& Training, 62(3), 351-366.

Pollack, J. M., Vanepps, E. M., \& Hayes, A. F. (2012). The moderating role of social ties on entrepreneurs ' depressed affect and withdrawal intentions in response to economic stress. Journal of Organizational Behavior, September 2010.

Robert, W., \& Brown, S. D. (2013). Social Cognitive Model of Career Self-Management: Toward a Unifying View of Adaptive Career Behavior Across the Life Span. America Psychological Associations, 60(4), 557-568. 
Şahin, F., Karadağ, H., \& Tuncer, B. (2019). Big five personality traits, entrepreneurial selfefficacy and entrepreneurial intention A configurational approach. International Journal of Entrepreneurial Behavior \& Research, 25(6), 118-1211.

Santi, N., Hamzah, A., \& Rahmawati, T. (2017). Pengaruh Efikasi Diri, Norma Subjektif, Sikap Berperilaku, dan Pendidikan. Jurnal Inspirasi Bisnis Dan Manajemen, 1(1), 63-74.

Santos, S. C., \& Liguori, E. W. (2019). Entrepreneurial self-efficacy and intentions: Outcome expectations as mediator and subjective norms as moderator. International Journal of Entrepreneurial Behaviour and Research, 26(3), 400-415.

Schwarz, E. J., Wdowiak, M. A., Almer-Jarz, D. A., \& Breitenecker, R. J. (2009). The effects of attitudes and perceived environment conditions on students' entrepreneurial intent: An Austrian perspective. Education and Training, 51(4), 272-291.

Segal, G., Borgia, D., \& Schoenfeld, J. (2002). Using Social Cognitive Career Theory to Predict Self-Employment Goals. New England Journal of Entrepreneurship, 5(2).

Sekaran, U., \& Bougie, R. (2016). Research Methods for Business: A Skill-Building Approach (4th ed.). John Wiley \& Sons Inc.

Shi, L., Yao, X., \& Wu, W. (2019). Perceived university support, entrepreneurial self-efficacy, heterogeneous entrepreneurial intentions in entrepreneurship education: The moderating role of the Chinese sense of face. Journal of Entrepreneurship in Emerging Economies, $12(2), 205-230$.

Silalahi, U. (2010). Metode Penelitian Sosial. Refika Aditama.

Smith, R. M., \& Combs, G. M. (2016). Understanding gender, creativity, and entrepreneurial intentions intentions. Education + Training, 58(3), 263-282.

Solesvik, M. Z. (2013). Entrepreneurial motivations and intentions: investigating the role of education major. Education + Training, 55(3), 253-271.

Tran, A. T. P., \& Korflesch, H. Von. (2016). A conceptual model of social entrepreneurial intention based on the social cognitive career theory. Asia Pacific Journal of Innovation and Entrepreneurship, 10(1), 17-38.

Vanevenhoven, J., \& Liguori, E. (2013). Introducing the Entrepreneurship Education Project. Journal Of Small Business Management 2013, 51(3), 315-328.

Wang, Y., Tseng, T. H., \& Wang, Y. (2020). Development and validation of an internet entrepreneurial self-efficacy scale. Internet Research, 30(2), 653-675.

Zhang, F., Wei, L., Sun, H., \& Tung, L. C. (2019). How entrepreneurial learning impacts one's intention towards entrepreneurship A planned behavior approach. Chinese Management Studies, 146-170.

Zhang, Y., Duysters, G., \& Cloodt, M. (2013). The role of entrepreneurship education as a predictor of university students ' entrepreneurial intention. International Entrepreneurship and Management Journal, 10, 623-641.

Zhao, X., Lynch, J. G., \& Chen, Q. (2010). Reconsidering Baron and Kenny: Myths and truths about mediation analysis. Journal of Consumer Research, 37(2), 197-206. 